\title{
A LUTA REVOLUCIONÁRIA PELA IGUALDADE SUBSTANTIVA PARA ALÉM DO CAPITAL
}

\author{
Lênin Tomazett Garcia ${ }^{1}$ \\ Anita C. de Azevedo Resende ${ }^{2}$
}

\begin{abstract}
Resumo: este artigo versa sobre a produção de um dos filósofos mais importantes no âmbito do marxismo, o pensador húngaro István Mészáros. O objeto de estudo deste trabalho foi o conceito de igualdade em Mészáros. Enfatiza-se como o conceito de igualdade, tal qual Mészáros desenvolve, tanto no conjunto de sua obra, como em textos mais específicos, ilumina a lógica interna de seu pensamento, tributário ao próprio Karl Marx, e por isso mesmo, de forma revolucionária, arquiteta internamente à sua elaboração, a tensão entre o lógico e o histórico no curso do método materialistadialético, na perspectiva de uma sociedade para além do capital.
\end{abstract}

Palavras-chave: Igualdade - Igualdade Formal - Igualdade Substantiva.

\section{THE REVOLUTIONARY STRUGGLE FOR SUBSTANTIVE EQUALITY BEYOND CAPITAL}

\begin{abstract}
: this article is about the production of one of the most important philosophers in the scope of Marxism, the Hungarian thinker István Mészáros. The object of study of this work was the concept of equality in Mészáros. It is emphasized that the concept of equality, as Mészáros develops, both in his work as a whole, and in more specific texts, illuminates the internal logic of his thought, tributary to Karl Marx himself, and for this very reason, to a revolutionary way, it architects internally to its elaboration the
\end{abstract}

\footnotetext{
${ }^{1}$ Doutor em Educação pela Universidade Federal de Goiás (UFG). Atua como professor na Faculdade de Educação Física e Dança (FEFD) da UFG. Trabalha com pesquisas em Ciências Sociais e Humanas, com ênfase em Sociologia da Educação e Educação de Jovens e Adultos, Ensino de Educação Física e Estágio Escolar. É membro do Núcleo de Estudos e Pesquisas em Educação, Psicologia e Cultura (NEPPEC) da Faculdade de Educação da UFG e do Grupo de Estudos e Pesquisas em Educação Física, Teoria Social e Educação (Grupo Pràksis) da FEFD/UFG. E-mail: lenintomazettgarcia@gmail.com

2 Doutora em Ciências Sociais pela Pontifícia Universidade Católica de São Paulo (PUC-SP), com estágio de pós-doutoramento em educação pela Faculdade de Educação da Universidade de São Paulo. Atua como professora titular da Universidade Federal de Goiás (UFG), integrando o quadro docente do Curso de Graduação em Pedagogia e no Programa de Pós-Graduação em Educação. É líder do Núcleo de Estudos e Pesquisas em Educação, Psicologia e Cultura (NEPPEC) da Faculdade de Educação da UFG. E-mail: aazeres@gmail.com
} 
tension between the logical and the historical in the course of the materialistic-dialectic method, so as to contemplate a society beyond the capital.

Key-words: Equality - Formal equality - Substantive Equality

\title{
LA LUCHA REVOLUCIONARIA POR LA IGUALDAD SUSTANTIVA MÁS ALLÁ DE CAPITAL
}

\begin{abstract}
Resumen: este artículo trata de la producción de uno de los filósofos más importantes en el ámbito del marxismo, el pensador húngaro István Mészáros. El objeto de estudio de este trabajo fue el concepto de igualdad en Mészáros. Se enfatiza que el concepto de igualdad, tal como lo desarrolla Mészáros, tanto en el conjunto de su obra, quanto en textos más específicos, ilumina la lógica interna de su pensamiento, tributario por el propio Karl Marx, y por esta misma razón, de manera revolucionaria, arquitecta internamente a su elaboración la tensión entre lo lógico y lo histórico en el curso del método materialista-dialéctico, para contemplar una sociedad más allá del capital.
\end{abstract}

Palabras clave: Igualdad - Igualdad formal - Igualdad Sustantiva.

\section{Introdução}

Quem quer que se ocupe honestamente do curso dos processos sociais e políticos contemporâneos irá se deparar com a destrutividade e o aprofundamento da desigualdade desenvolvidos sob a batuta do capital e enquanto sua base mais sólida. Para além das investidas do capital na esfera produtiva estão em questão as derivações processadas em todas as esferas da vida humana que atingem, para além da destruição das bases materiais, a organização politica e a identificação dos interesses de classe. Dessa perspectiva, o horizonte para as lutas em direção à emancipação humana parece estar comprometido pela falência de um projeto civilizatório que faça frente à barbárie cada vez mais legitimada. Os limites da igualdade substantiva se ocultam na forma mercantil das relações sociais desiguais e aparecem como equidade e justiça social formal. A classe trabalhadora enfrenta tempos de restrição e ativação dos limites históricos da sociabilidade do capital. Estão em pauta ataques perversos à sobrevivência humana ocultando a desigualdade estrutural do capital sob o véu místico de ilusões jurídicas e formais.

Uma contribuição fundamental ao descortino dos processos e estruturas que estão em causa nos desenvolvimentos do capital, no estabelecimento da mediação entre essa particularidade histórica e a totalidade social e no enfrentamento das contradições sociais para a emancipação humana é a elaboração magistral de István Mészáros (2006a); (2009), acerca o conceito de igualdade substantiva. Enquanto 
elaboração sintética de uma realidade histórica, o conceito elucida e sintetiza a concreticidade dos desenvolvimentos do capital, revela aí a desigualdade como limite estrutural e postula as condições da emancipação humana.

A partir de Mészáros, o conceito de igualdade substantiva põe o debate da justiça e das relações sociais num patamar de radicalidade imbricado à condição universal e revolucionária da classe trabalhadora. Ou seja, a classe trabalhadora é a única que pode pôr em pauta, na sociedade capitalista, com radicalidade e universalidade, a questão da verdadeira igualdade social que será construída sob a base de uma sociedade regida por produtores livremente associados. A radicalidade e importância dessa elaboração implicará o enfrentamento teórico e prático de concepções diversas acerca dos sujeitos históricos que remeterão tanto aos pensadores clássicos como Hegel ou Kant quanto com representantes das ilusões erigidas por apologistas do capital como Hayek e seus seguidores. Uma sociedade livre, constituída por produtores livremente associados é uma realidade que só pode ser posta em ação pela superação dos limites auto-impostos e destrutivos do próprio capital pela via revolucionária dos trabalhadores, ou seja, da classe que vive do trabalho (ANTUNES, 2001).

Ao tempo que exige por em ação a classe, a "igualdade substantiva" põe em curso a dimensão perversa da produção material da existência que se manifesta à razão comum sob formas ilusórias de existência de produtores iguais e justapostos no âmbito das relações materiais de produção capitalista. Esta ilusão necessária e materialmente sustentada sob a ocultação da expropriação do trabalho, é mediação fundamental das lutas de classes na particularidade histórica do sociometabolismo do capital.

\begin{abstract}
A julgar pela maneira como poderiam ser caracterizadas as formas conhecidas do relacionamento interpessoal socialmente estabelecido entre mulheres e homens utilizando o critério da livre determinação humanamente realizadora de suas vidas por pessoas autônomas interagindo sobre a base da verdadeira igualdade -, "todo nível de desenvolvimento" realizado no decorrer da história não é hoje muito mais alto do que alguns milhares de anos atrás, apesar de todo o avanço na produtividade (MÉSZÁROS, 2006a, p. 268).
\end{abstract}

Essa tese fundamental já ressoava em Marx e Engels desde o Manifesto do Partido Comunista. Os desenvolvimentos históricos precedentes fizeram agudizar na ordem capitalista a sua base constitutiva: a luta de classes. A contradição entre forças produtivas e relações de produção, se expressa nesta ordem sociometabólica, cobrando o custo de milhares de vidas em troca da concentração de riqueza e poder 
a ainda acompanhada da perversidade de manifestar-se a todo tempo como uma organização jurídico-política estabelecida com base na igualdade.

Está em curso a mistificação que inverte a questão da igualdade e a apresenta como algo a ser buscado/conquistado no âmbito jurídico e/ou político enquanto fundamento individual. Para que houvesse igualdade substantiva, uma das premissas fundamentais desta ordem sociometabólica haveria de ser superada, qual seja: a hierarquização das relações sociais.

A estrutura de comando do capital, sempre muito hierárquica (ainda que historicamente mutável em sua forma), é a consequência inevitável da determinação incorrigível do sistema do capital como um sistema de relações de poder antagônicas, em que o poder de controle está inteiramente separado dos produtores e cruelmente imposto sobre eles (MÉSZÁROS, 2006a, p. 269).

Os limites para a realização da igualdade substantiva se acentuam quanto mais o capitalismo busca saídas para sua crise que, estrutural e longe de ser superada, deve ser compreendida enquanto um processo contínuo que se aprofunda a partir da contradição entre a necessária expansão da produção e a diminuição do consumo e da circulação. A expansão destrutiva, realizada na esteira da acumulação e do lucro, não poupa as formas diversas da sociabilidade e atinge objetiva e subjetivamente a classe trabalhadora impondo-lhe desde a privação, o pauperismo, a alienação, a perda de direitos conquistados, entre mais. E mesmo por isso, os desenvolvimentos do capitalismo deixam a claro os limites da igualdade formal e a urgência de sua superação.

Esta condição histórica do capital aponta a necessidade de sua superação, ou seja, mobilizar forças em direção da igualdade substantiva, tal como o pensador húngaro nos convida. Eis um enfrentamento prático e teórico, histórico e lógico, que pressupõe e determina uma consciência de classe revolucionária frente às formas mistificadoras de desenvolvimento e produção da história.

\section{Fundamentos da igualdade e da desigualdade na obra de Ístvan Mészáros}

Ao refletir sobre a igualdade na sua expressão universal e substancial à sociabilidade humana, Mészáros (2006a) toma como emblema as relações internas à constituição da família. Para tal, retoma especialmente o itinerário da incorporação da força de trabalho feminina no complexo arranjo industrial da produção capitalista na configuração da família tradicional. 
Não por acaso, a constituição das mulheres enquanto força de trabalho é uma questão relevante. Primeiro, porque este é um dos limites no âmbito de vertentes do pensamento marxista que desconsiderou a questão das mulheres e seu protagonismo enquanto classe trabalhadora. Em que pese o fato dessa desconsideração ser engendrada na própria história, se relacionar com momentos do desenvolvimento do capitalismo e se saber que nenhuma teoria tem por si mesma força para instituir a realidade; o fato é que a questão da mulher foi relegada a um segundo plano. Quando a realidade exigiu a incorporação da força de trabalho feminino na produção, a questão das mulheres trabalhadoras exige compreender essa no coletivo da classe trabalhadora em suas diferentes frações.

Segundo, porque o próprio sociometabolismo do capital incorpora e converte a mulher como uma força de trabalho da qual pode extrair um quantum a mais de valor na medida em que: i) força a entrada das mulheres, como uma fração inferior aos homens, no mercado de trabalho devido aos imperativos de reprodução da força de trabalho da classe trabalhadora; ii) intensifica a exploração na força de trabalho masculina, aproveitando do discurso de justiça e igualdade; reduz os salários dos homens para aproximá-los aos salários das mulheres (ao invés de elevar os salários das mulheres), para com isso apresentar números mais aceitáveis de equivalência entre os salários de homens e de mulheres e; reforça e aprofunda as relações hierarquizantes e autoritárias no interior da classe trabalhadora e na sociedade como um todo.

A entrada em massa das mulheres na força de trabalho durante o século XX, em extensão tão significativa que até hoje elas chegam a constituir maioria nos países de capitalismo avançado, não resultou em sua emancipação. Em vez disso, apareceu a tendência de generalizar para toda a força de trabalho a imposição dos salários mais baixos a que as mulheres sempre tiveram de se submeter (MÉSZÁROS, 2006a, p. 272).

A incorporação da força de trabalho das mulheres não significa nenhum avanço nas suas condições de vida ou na sua emanciapação. Ao contrário, significa a submissão de novos agentes aos mesmos procedimentos de exploração e imposição aos quais está submetida a classe. A mulher é incorporada como classe a ser explorada, a par de que essa aprofundamento da exploração e a extensão da desigualdade lhe seja apresentada como promessa de condições de igualdade e emancipação. A desigualdade se apresenta aí como igualdade de oportunidades individuais e revela o fetiche necessário à ocultação da condição coletiva de classe a ser explorada. 
Destarte, o segredo desse processo não se aloja na consciência individual. Sua origem pode ser retomada, desde Marx, na afirmação da produção como fundamento do processo de desenvolvimento do capital. Em seus escritos fundamentais, e principalmente nos Grundrisse, Marx já indica que é no momento da produção que se definem as determinações fundamentais do desenvolvimento capitalista. Essa tese, retomada por Mészáros (2006a), permite compreender as bases sobre quais se assentam a questão da desigualdade.

\section{Produção, distribuição e consumo à sombra da incontrolabilidade}

A questão da produção, tal qual Marx a desenvolveu em seus escritos, é melhor apreendida quando observa-se o itinerário do trabalho como forma de assalariamento. 0 ponto de partida para compreender esse processo deve ser ele mesmo: produção, desenvolvimento das forças produtivas e relações de produção:

Hay que hacerse cargo de que las nuevas fuerzas productivas e relaciones de producción no se desarrollaron a partir de la nada, ni del aire, ni d las entrañas de la idea que pose a sí misma; sino en el interior de desarrollo existente de la producción y de las relaciones de propiedad tradicionales y contraponiéndose a ese desarrollo y esas relaciones (MARX, 1986, p. 219).

A relação social de produção sob a forma de renda, que faz da terra instrumento de gerar capital, seja pela especulação fundiária, ou seja pelo emprego direto de força de trabalho, representa uma diferença qualitativa no sentido social atribuído ao meio de produção. 0 que o trabalhador busca na terra não é o elemento que nela se objetiva diretamente e sim o equivalente geral de todas as mercadorias. "Lo que vende es la disposición de su trabajo, el cual es um trabajo determinado, determinada pericia, etcétera" Marx (1986, p. 224).

A moderna propriedade da terra a configura enquanto instrumento produtivo. Ora, produtivo na medida em que seja instrumento capaz de extrair mais-valia, de desenvolver o assalariamento do trabalho:

Si es rico, el antiguo propietario de la tierra no necesita de capitalista alguno para convertirse en terrateniente moderno. Le basta con transformar a sus trabajadores en asalariados y con producir con vistas al beneficio, en lugar de hacerlo con vistas al rédito. En su persona están presupuestos el arrendatario y el terrateniente modernos (MARX, 1986, p. 218).

E ainda:

No cabe duda alguna, pues, de que el trabajo asalariado en su forma clásica, como aquello que impregna a la sociedad en toda su amplitud y se convierte en base de la 
misma, en lugar de la tierra, no es creado sino por la moderna propiedad de la tierra, esto es, por la propiedad de la tierra en cuanto valor creado por el capital mismo. De ahí que la propiedad de la tierra nos vuelva llevar al trabajo asalariado (MARX, 1986 p. 218).

0 trabalho assalariado assume um sentido diferenciado: como base do capital enquanto organização societal e também como um trabalho no qual o trabalhador se põe no objeto e nele se perde; "para el trabajador el trabajo nunca tiene valor de uso directo. La base entera de aquélla es el trabajo como valor de cambio y como creador de valor de cambio" Marx (1986, p. 373).

Ao trabalho assalariado está determinada a participação na distribuição da produção e, nesse sentido, o conjunto das relações sociais determinam materialmente a produção e reprodução contraditória que se desenvolve o trabalho:

Que el obrero pueda pasar a la transformacíon de la moeda en dinero, al ahorro, demuestra tan sólo que su relacíon es la de la circulacíon simple; puede ahorrar más o menos, pero no puede pasar de esto; únicamente puede realizar lo ahorrado si amplía momentáneamente el círculo de sus disfrutes. Pero lo importante - y lo que influye en la determinacíon de la relacíon misma - intercambio. La riqueza uiversal, en cuanto ilusíon, lo estimula, lo hace laborioso (MARX, 1986, p. 232).

Aparentemente pode aparecer ao trabalhador que, ao receber o salário, ele está sendo pago por todo o trabalho realizado num determinado tempo (um mês de trabalho, por exemplo). Quando recebe esta quantia, parece que lhe é dado um pagamento referente a todo um ciclo toda produção. É como se, ao final de um mês, a quantia de dinheiro que o trabalhador recebe fosse equivalente ao pagamento de um mês de trabalho. Na realidade, o que lhe é dado é somente uma parte, a outra Marx chama de lucro ${ }^{3}$.

Acontece que isso não é transparente, é oculto. É negativo à aparência, pois os valores que são acrescidos à mercadoria no processo produtivo não são transparentes, a esta é plasmado (agregado) um quantum de trabalho, de valor que não é "visível" no intercâmbio entre trabalhador e capitalista; ou ao menos não entra nos cálculos do salário.

\footnotetext{
${ }^{3}$ Este lucro pode ser repartido entre os capitalistas, seja como for, não diz nada acerca de como se gera este lucro: "De todos los beneficios que obtiene el capital, es decir la masa total de los capitalistas, hay que deducir: 1) La parte constante del capital; 2) el salario, o el tiempo de trabajo objetivado que se requiere para reproducir la capacidad viva de trabajo. Los capitalistas, pues, no pueden repartirse nada entre si a excepción del plusvalor. Las proporciones - justas o injustas - en las cuales se distribuyen entre si ese plusvalor, no modifican absolutamente nada en el intercambio entre el capital y el trabajo.” (MARX, 1986, p. 378)
} 
Quando as mercadorias chegam na esfera da circulação, estas são vendidas pelo seu próprio valor. Não é na circulação que se criará o valor das mercadorias, visto que este o fora agregado no ato da produção. Na circulação, o valor se realiza negativamente, enquanto na produção ocorre a tensão entre valorização da mercadoria cristalizada e desvalorização do trabalho como mercadoria. É na produção, enquanto processo produtivo que não se esgota num momento restrito, que se produz a ocultação.

Se o capitalista pagasse ao trabalhador o equivalente total pela sua atividade produtiva, de onde sairia o lucro? Da venda da mercadoria, claro. Nada mais falso e aparente. Afinal, se o lucro se produzisse no momento da troca, todas as mercadorias estariam obrigadas a serem, neste momento, fonte de rendimentos. E resultaria que qualquer vendedor de mercadorias gastaria todo seu lucro ao comprar mercadorias dos outros vendedores. De outra parte, se poderia objetar que o lucro adviria da expansão dos pontos de consumo. 0 capitalista vende mais do que compra e daí obtem seu lucro. Neste caso, o rendimento seria obtido pela expansão do sistema, pela criação de novos mercados, pela difusão de novos valores de uso e etc. Isso poderia ser considerado mas restaria arguir a origem da taxa média de lucro do capitalista superior à correspondente expansão do capital. 0 limite desses argumentos parece estar neles mesmos. Já nos Grundrisse, Marx questiona acerca da possibilidade da valorização da mercadoria ocorrer na circulação. Entretanto, as pesquisas de Marx encontraram na produção, as mediações constitutivas do valor, quais sejam: o trabalho social e seus engendramentos (mais-valia absoluta, relativa, lucro, salário).

Assim, não é a vontade ou a idéia que constituem o real. É a própria materialidade, o próprio objeto que responde por si mesmo às perguntas problemáticas geradas na materialidade mesma. 0 fato de que os seres humanos se relacionem como coisas e as coisas carreiem atributos humanos, não é algo que se produza no momento do consumo das mercadorias, nem no momento de distribuição e isto está definido no momento mesmo da produção. Ainda que na fantasmagoria da realidade aparente, possa parecer o contrário.

O sistema do capital não é apenas "aparentemente irracional", mas completa e irremediavelmente irracional; além disso não é "impessoal" em sua natureza real, mas apenas aparentemente impessoal. Ou seja, ele é impessoal apenas devido ao fetichismo da mercadoria historicamente prevalecente, que faz com que um tipo de relação entre os homens - sob o modo de controle sociometabólico do capital assuma diante de seus olhos "a forma fantástica de um relacionamento entre coisas", para que sua própria ação social assuma a forma de ação de objetos que dominam os produtores em vez de serem por eles dominados (MÉSZÁROS, 2006a, p. 281). 
Tal amálgama de relações fetichizadas são o mote de um sistema de sociometabolismo incontrolável. Os "resultados" do conjunto da produção social interditam e impedem aos sujeitos da produção a identificação, o reconheccimento e o desenvolvimento de suas potencialidades genéricas. Ao contrário, o trabalhador se sente impotente frente a um sistema que parece ter vida própria e incontrolável.

Nos Grundrisse (1857-1858) Marx debate com Proudhon e desmonta o pensamento afirmativo de que as causas das crises do capital se originem na incapacidade da massa consumir, de adquirir o produto que produz:

Proudhon, que por cierto oye repicar las campanas, pero nunca sabe donde, deriva la superproducción de "que el obrero no pude volver a comprar su producto." Con eso quiere decir que al producto se le caga interés y el beneficio, o que el precio del producto está recargado respecto de su valor real. Esto demuestra, d'abord que no entiende nada de la determinación del valor, la cual habla en general (MARX, 1986, p. 378).

A questão não pode ser "resolvida" no valor-de-uso, muito menos no campo da distribuição ou do consumo das mercadorias. 0 valor pelo qual as mercadorias são trocadas corresponde ao seu valor real. Acontece que o quantum de trabalho objetivado na mercadoria é negativo à aparência e acrescido no próprio processo produtivo. Aí, nesta tensão, dá-se a criação de riqueza e a desvalorização do trabalho.

A crise de superprodução do capital que aparece como causa pressuposta de um mercado consumidor incapaz de absorver a quantidade de produção é, na verdade, o complexo processo de desenvolvimento dos fundamentos de expansão qualitativa e quantitativa - do capital. As bases da crise não estão somente no intercâmbio ou na distribuição; elas são de outra ordem.

El intercambio no modifica das condiciones internas de la valorización, pero las proyecta hacia el exterior; les da su forma recíprocamente autónoma y deja así existir a la unidad interna solamente como necesidad interna que, por tanto, se manifiesta exteriormente y de manera violenta en las crisis (MARX, 1986, p. 407).

A crise se desenvolve mediada pelo processo de valorização e desvalorização das mercadorias. 0 intercâmbio realiza a produção do capital pois, sem esse, a valorização "no existiría en cuanto tal. Sin intercambio se trataría solamente de la medida del valor de uso producido, y en general sólo del valor de uso." Marx (1986, p. 407)

A esfera da circulação das mercadorias realiza o valor, projeta-o. E isso se dá na materialidade, no momento da produção do lucro. Portanto, esta mesma esfera se projeta exteriormente, na superficialidade, como causa das crises. No entanto, ela é 
uma das mediações do processo pois existe uma ordem dessas determinações que é estabelecida na realidade tais como: a ocultação do trabalho plasmado na mercadoria, a geração de riqueza, a expansão e concentração do capital e a permanente tensão gerada pelo desenvolvimento das forças produtivas:

Un crecimiento general y repentino de las fuerzas productivas desvalorizaría relativamente todos los valores existentes, objetivados por el trabajo en un estadio inferior de las fuerzas productivas, y por consiguiente destruiría capital existente, así como capacidad de trabajo existente (MARX, 1986, p. 406).

A 'depressão' econômica levada em sua essência, sintetiza a relação entre a baixa dos preços, a ocultação do valor - e mais ainda, do trabalho -, e traz à tona a ocultação do capital sob a forma dinheiro, a confusão entre preço e capital, e por fim impele violentamente, a destruição do capital e do trabalho vivo ${ }^{4}$ :

En una crisis - en una depreciación general de los precios - hasta cierto punto se produce, al mismo tiempo, una desvalorización o destrucción general de capital. La desvalorización puede ser general, absoluta, no sólo relativa, como la depreciación, porque el valor no sólo expresa, como el precio, una relación de una mercancía con otra, sino la proporción entre el precio de la mercancía y el trabajo objetivado en ella, o entre una cantidad de trabajo objetivado de la misma calidad y otra cantidad (MARX, 1986, p. 406).

O engendramento da crise está pois na radicalidade posta na origem da produção do capital, ou seja, nos processos contraditórios de sua manutenção enquanto ordem sociometabólica. Afirmar que esses processos se alojam na entre capital e trabalho é necessário, mas não suficiente. Para além, é necessário abarcar a totalidade aberta na qual a materialidade se constitui e a contradição se desenvolve. Essa contradição fundamental abarca também o segredo do funcionamento de um sistema que opera ocultando seu próprio funcionamento. É necessário portanto apreender as mediações constitutivas deste processo de produção que se desenvolve arrastando os limites e as misérias de seu próprio funcionamento para garantir sua continuidade.

A produção e reprodução desse sistema é carregada de mediações que lhe dão concreticidade e amadurecimento. A produção de riqueza que não se destina às necessidades do gênero humano e tampouco à sua emancipação e realização. A

\footnotetext{
${ }^{4}$ Em Marx, acompanhamos o autor quando investiga o dinheiro. Este aparece como a primeira determinação de riqueza. Como o equivalente geral das demais mercadorias colecionadas pelos burgueses ricos. Entretanto, levadas em sua essência, as categorias: trabalho, valor e capital permitem revelar processos ocultos sob a forma dinheiro na sociedade das mercadorias. O desvelar deste processo de ocultação é complexo e Marx o fizera em O Capital, no Grundrisse, em A Miséria da Filosofia, em Para a Crítica da Economia Política, para citar alguns textos fundamentais, há outros momentos em que este processo é analisado.
} 
riqueza e o chamado progresso da civilização se tecem numa totalidade que envolve o lucro, a renda da terra, a apropriação do sobretrabalho, a ocultação da valorização da mercadoria no processo produtivo e a venda de seu valor real no mercado como se não houvesse já contido na mercadoria o qüiproquó complexo e negativo à aparência

\section{Radicalidade e insurgência: a crítica ao fetiche da igualdade.}

Segundo Mészáros (2006a, p. 190-198) os apologetas da classe burguesa encontram a saída para a igualdade apostando no mercado. Exemplar nisso é Hayek que, muito inteligente e impessoal, prefere a frieza de um poder aparentemente instituído sem a participação dos homens. Ilusoriamente, a aposta no mercado se aponta como uma saída pois a i) tendência geral ao formalismo e a ii) exteriorização do poder e sua consequente anteposição ao homem fortalece, produz e reproduz a lógica sociometabólica do capital em sua estrutura alienante do ser ante a si mesmo, ante os produtos de seu trabalho e diante do conjunto da humanidade. Mészáros (2009, p. 27-46); (2006b, p.135-138). Neste sentido, é coerente com as formas do capital de produção metabólica a escolha e adesão a um poder que esteja localizado (ainda que aparentemente), fora da dimensão humana, por assim investir-se de uma áurea rósea e justa. A mistificação se radica na produção da própria materialidade.

A impressão de independência e neutralidade para definir e encaminhar o poder político retoma uma pureza e uma imparcialidade que somente sendo reais na aparência, dariam a este ente externo a autoridade de decisão. Este ente puro seria o mercado, que apostando em sua aparente impessoalidade poderia, ele sim, regular de forma justa as relações sociais.

A aposta na racionalidade do mercado revela em si mesma tanto a preferência pela impessoalidade, pela frieza, pela irracionalidade, pelo poder instituído na exterioridade, tal qual a áurea pentecostal que tanto idealiza um juiz "imparcial" de fora, como também defende um tipo de sujeito submisso à verticalidade do mercado, um sujeito incapaz e limitado frente ao poder com o qual se defronta como negativo. 0 estranhamento frente ao mercado e à sua mão invisível, aparentemente independente da vontade dos próprios sujeitos, a definir a forma e substância da produção material da existência provém da forma mesma da mercadoria. A fetichização das relações sociais se engendra no processo mesmo da produção e constitui internamente todo itinerário contraditório do metabolismo social. 
Toda a conversa sobre "imparcialidade" e "justiça" como base da "igualdade" coloca o carro na frente dos bois mesmo quando seja sincera, e não uma camuflagem cínica para a negação das mais elementares condições de igualdade. A definição das questões em jogo em termos de "igualdade de oportunidades" está nas mãos dos que anseiam por evitar qualquer mudança nas relações de poder prevalecentes e nas correspondentes hierarquias estruturalmente impostas, oferecendo a promessa irrealizável de "oportunidade igual" diante dos críticos da desigualdade social como a cenoura inalcançável na frente do burro. A promessa de "imparcialidade" e "justiça" em um mundo dominado pelo capital só pode ser o álibi mistificador para a permanência da desigualdade substantiva (MÉSZÁROS, 2006a, p. 305).

Todas as justificativas que se embasem no mercado ou na lógica do mercado será expressão mais ou menos avançada das ilusões históricas que o próprio mercado erige como instância "pura" e justa para estabelecer as relações sociais de produção material de existência. A ativação dos limites históricos do capital revela e repõe a necessidade histórica da transformação e superação deste sistema metabólico que possui a desigualdade substantiva como corolário de sua expansão e continuidade.

O sistema do capital, para se manter vivo e se expandir, exige expandir suas misérias por toda a sociedade e concentrar suas riquezas nas mãos de muito poucos, dos representantes exclusivos da burguesia. Assim, o sistema do capital só se expande na medida em que expanda também a desigualdade substantiva como fundamento do funcionamento social. Como lei geral, essa tendência da acumulação capitalista se recria de forma ainda mais perversa nos países de capitalismo dependente.

A desigualdade substantiva toma a sua forma mais perversa nas economias nacionais aonde o capital se desenvolveu com base nos laços de dependência e num amálgama de tendência ao imperialismo e autocracia, se fez história sob o véu místico da extensão da igualdade e do progresso. Fernandes (2006).

O sistema do capital se articula numa rede de contradições que só se consegue administrar medianamente, ainda assim durante curto intervalo, mas que não se consegue superar definitivamente. Na raiz de todas elas encontramos o antagonismo inconciliável entre capital e trabalho, assumindo sempre e necessariamente a forma de subordinação estrutural e hierárquica do trabalho ao capital, não importando o grau de elaboração e mistificação das tentativas de camufla-la (MÉSZÁROS, 2006a, p. 19).

A subordinação da ontologia humana à particularidade histórica do capitalismo é em si um constante devir de limitações auto-impostas que, em sua aparência, não resultam da ação dos indivíduos e se lhe defrontam como um ente estranho correspondente ao mesmo outro ente estranho convocado da quimera restante, 
chamado mercado, para arrumar e regular toda essa contradição irradiada em todas as dimensões da vida.

A instituição da igualdade formal é irradiação desta contradição insolúvel que convoca em sua guarda o Estado sob o constante espectro da luta de classes. Em síntese, Mészáros (2009, p. 43) esclarece que a tendência geral ao formalismo é um corolário da irracionalidade substantiva tributaria à subordinação do trabalho ao processo de criação do capital. Mészáros (2006a, p. 281). Além disso: “o que gera essa tendência ao formalismo estipulador é a necessidade de extinguir os conflitos no plano da teoria, deixando seus elementos materiais intocados no mundo prático" Mészáros (2009, p. 43).

Para que a igualdade possa existir no plano da razão formalizada, enquanto expressão da irracionalidade constitutiva de todo complexo arranjo produtivo gerador de lucros e originada na própria produção sociometabólica, é necessário que questões fundamentais da produção material da existência humana sejam deixadas "de fora". Aí é que se faz urgente apreender as inversões e ocultações produtoras e produzidas na própria materialidade social para captar os desenvolvimentos da história para superar o plano das leis gerais do contrato formal. Mészáros (2006a, p. 278). Somente assim se poderá pretender a realização da igualdade substantiva.

Não poderia haver violação mais absurda da lógica do que a inversão das relações
causais existentes, para se visualizar a capacidade do sistema de introduzir todos os
aperfeiçoamentos desejáveis nesse "macrocosmo" com a premissa inalterável da
manutenção das relações de poder material da subordinação estrutural do trabalho
ao capital, sempre reforçadas pela estrutura de comando inevitavelmente
hierárquica (e, portanto, impossível de ser reformada em qualquer sentido). Mas é
precisamente isso que encontramos em todas as reivindicações de igualdade, tanto
nas já estabelecidas como nas que estão a ponto de ser instituídas - inclusive o apelo
ritual à ideia de "igualdade de oportunidades" - e postuladas pelos defensores do
sistema do capital em suas idealizações da "sociedade industrial moderna" e da
"sociedade de mercado" com preocupações sociais (MÉSZÁROS, 2006a, p. 269).

Há que se distinguir que posta essa radicalidade, não pode-se confundir as falsas possibilidades de se atingir igualdade. Igualdade tal qual Mészáros postula está radicalmente ancorada na noção de superação do capital como forma de metabolismo social. A superação do Estado do capital e do trabalho assalariado hão de serem superados historicamente para que a igualdade real, ou a igualdade substantiva possa emergir no âmbito das relações entre os produtores livremente associados. 
Desde a tendência geral ao formalismo, à instituição do poder impessoal e estranho aos sujeitos (que ao ser produzido pelo conjunto da humanidade se volta contra ela mesma e aparentemente como um ente destituído de humanidade) tal como acontece com a promessa do mercado de ser regulador justo das relações sociais; as irradiações mistificadoras da igualdade se frutificam arraigadas a palavras de ordem dos sicofantas da burguesia, tais como, democracia direta, igualdade substancial e igualdade de oportunidades.

Todas podem angariar adesão de considerável alcance, mas jamais a história deixará de revelar seus limites à sombra da incontrolabilidade das contradições do capital. Serão necessárias outras operações malabaristas de prolongar o ocultamento dos limites de um sistema que já anuncia internamente à sua marcha histórica a necessidade da própria superação, ou a barbárie como forma permanente e sempre reiterada de vida, que implica numa monumental ofensiva às possibilidades históricas de uma vida humana livremente associada.

\section{Considerações Finais}

Necessariamente, como um dos maiores representantes do materialismo histórico-dialético no mundo todo, István Mészáros elabora toda sua obra e internamente ao seu pensamento está a histórica necessidade de superação do sistema do capital enquanto ordem sociometabólica.

A condição preliminar do movimento na direção de uma ordem social justificável é
mudar a ordem invertida que hoje predomina entre justiça e igualdade. A única
maneira possível de realmente dar uma base à própria justiça, retirando-a do reino
da mistificação ideológica e da manipulação cínica, é fazer com que a igualdade
substantiva se torne o princípio eficaz de regulamentação de todas as relações
humanas. Não há outra maneira, ainda que os "legisladores ideais" - que tentariam
instituir a "imparcialidade" da "oportunidade igual" - enrubescessem diante da
pressão de suas boas intenções acumuladas. Em outras palavras, somente a
igualdade substantiva pode ser a base de uma justiça significativa, mas nenhuma
justiça legalmente decretada criaria uma igualdade legítima - ainda que isso pudesse
acontecer, e este naturalmente não é o caso (MÉSZÁROS, 2006a, p. 306).

Essa contribuição relega a toda a classe trabalhadora grande contribuição histórica enquanto a única classe capaz de revolucionar radicalmente e emanciparse e a todas as demais classes existentes do sociometabolismo do capital, seja qual sua forma histórica numa determinada práxis social. Para o Brasil e demais países de capitalismo periférico esta premissa histórica tece universalidade e articula em sua estrutura lógica, passado, presente e o futuro da luta de classes. 
Enquanto na luta de classes a classe trabalhadora não produzir historicamente a igualdade substantiva como forma de intercâmbio entre os produtores livremente associados, a sua luta será sempre pela sua efetivação histórica. Nos ciclos incontroláveis de crise do capital, e em suas depressões clássicas sob a forma militar e de avanço da barbárie, a igualdade substantiva emerge como no seio das relações sociais como uma complexa "resposta" aos problemas e contradições que a humanidade vem se defrontando como resultantes da ação da própria humanidade no metabolismo social, compreendidas como o conjunto das mediações de primeira e de segunda ordem. Mészáros (2006a, p. 179).

O pensamento marxista, em sua produção, é uma teoria da história que reivindica para si fazer história da teoria. Submete ao tribunal da razão os próprios fundamentos de sua produção, e radica na história o crivo de radicalidade e validade da própria lógica interna. A teoria de Mészáros não é algo que fica para a humanidade, relegada aos livros, possíveis de serem corroídos pelo tempo, mas sim, tecem no fio da história o tempo dela mesma e se faz assim constitutiva no itinerário histórico da luta de classes.

Além de revelar os limites da sociedade colecionadora de mercadorias, ao revelar os limites dessa sociedade, anuncia a necessidade histórica de sua superação dialética, e neste sentido se faz presente em todo curso da história da luta de classes rumo à superação do capital como princípio organizador das relações materiais de produção. Os títulos dos seus escritos são emblemáticos e já sintetizam por si próprios o itinerário da humanidade para além do capital.

\section{Referências}

ANTUNES, Ricardo. Os sentidos do trabalho: ensaio sobre a afirmação e a negação do trabalho. 5a edição. São Paulo, Boitempo, 2001.

FERNANDES, Florestan. A Revolução Burguesa no Brasil: ensaio de interpretação sociológica. 5ª edição. Ed.: Globo, São Paulo, 2005.

MARX, Karl. Elementos fundamentales para la crítica de la economia política. (Grundrisse)1857-1858. Vol. I. 14a Edição. Tradução: José Aricó, Miguel Murmis e Pedro Scaron. Ed.: Siglo XXI, San Ángel, 1986. 
MÉSZÁROS, István. Para além do Capital: rumo a uma teoria da transição. Tradução de Paulo Cezar Castanheira e Sérgio Lessa. Ed.: Boitempo, São Paulo, 2006a. Total de páginas: 1102.

. A teoria da alienação em Marx. Tradução de Isa Tavares. Ed. Boitempo, São Paulo, 2006b. Total de páginas: 293.

Estrutura social e formas de consciência: a determinação social do método. Tradução de Luciana Pudenzi, Francisco Raul Cornejo, Paulo Cezar Castanheira. Ed. Boitempo, São Paulo, 2009. Total de páginas: 309.

Recebido em 18/04/2018

Aprovado em 03/08/2018 